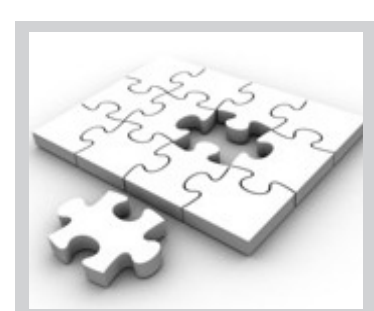

In an effort to facilitate the selection of appropriate peer reviewers for the African Journal of Disability, we ask that you take a moment to update your electronic portfolio on http:/ / www.ajod.org for our files, allowing us better access to your areas of interest and expertise, in order to match reviewers with submitted manuscripts.

If you would like to become a reviewer, please visit the journal website and register as a reviewer.

To access your details on the website, you will need to follow these steps:

1. Log into the online journal at http://www. ajod.org

2. In your 'user home' [http://www.ajod.org/ index.php/ajod/user] select 'edit my profile' under the heading 'my account' and insert all relevant details, bio statement and reviewing interest.

3. It is good practice as a reviewer to update your personal details regularly to ensure contact with you throughout your professional term as reviewer to the African Journal of Disability.

Please do not hesitate to contact us if you require assistance in performing this task.

Publisher: publishing@aosis.co.za

Tel: +27 219752602

Fax: +27 219754635

\section{Acknowledgement to reviewers}

The editorial team of the African Journal of Disability recognises the value and importance of the peer reviewer in the overall publication process - not only in shaping the individual manuscript, but also in shaping the credibility and reputation of our journal.

We are committed to the timely publication of all original, innovative contributions submitted for publication. As such, the identification and selection of reviewers who have expertise and interest in the topics appropriate to each manuscript are essential elements in ensuring a timely, productive peer review process.

We would like to take this opportunity to thank all reviewers who participated in shaping this issue of the African Journal of Disability:

Amelia van der Merwe
Anand Mhatre
Anita van der Merwe
Anlia Pretorius
Brett Bowman
Bronwyne Coetzee
Camilla Hansen
Chiwoza R. Bandawe
Clare Harvey
Cosmos Yarfi
Desire Chiwandire
Diane Browder
Elsje Scheffler
Estelle Swart
Ester Munalula-Nkanu
Gabrielle G. Kelly
Gerard Goggin
Gert van Rooy
Gloria Marsay
Gubela Mji
Heidi Lourens
Jennifer Jelsma
Johan Borg
Jon Duvall
Joy Wee
Julia Bingham
Karen L. Rispin
Kate A. Sherry
Kendra Leith
Lana van Niekerk
Lisa Saville-Young
Lynn Clouder
Madeleine Duncan
Madoda P. Cekiso
Mahender Mandala

Marcia Lyner-Cleophas

Margaret M. Wazakili

Margie Schneider

Maria Marchetti-Mercer

Maria L. Toro

Martha Geiger

Mary Goldberg

Mary Wickenden

Michael Evangeli

Michael Wehmeyer

Nina Yssel

Oliver Mutanga

Paul I. Chappell

Pragashnie Govender (nee' Naidoo)

R. Lee Kirby

Rebecca A. Matter

Richard Vergunst

Ronald Kirby

Roshan Galvaan

Sara Bass

Sara Munera Orozco

Sarah M. Anjos

Sarah Rule

Selete Avoke

Shona McDonald

Stephanie Nixon

Stine H. Braathen

Surona J. Visagie

Teresa Plummer

Tone Oderud

Veloshnee Govender

Verusia Chetty

Vic McKinney

Wayne Derman

Zelda Coetzee 